\title{
Rejuvenating the Ovate Pontic
}

\author{
Mohsin Atibuddin Quazi, Jaykumar Gade, Krishnakumar Lahoti, Vandana Gade
}

\begin{abstract}
The restoration of esthetics along with maintenance of healthy gingival tissues is of utmost importance when treating the maxillary anterior region. The resorption of the residual ridge or the irregularities in soft tissue often results in an unfavorable relationship with the pontic, compromising the final esthetic outcome. Various techniques have been developed to overcome this problem, among which tissue conditioning with controlled pressure proves out to be a boon as it is noninvasive. This article presents a case of a 27 -year-old male with a missing central incisor with irregular soft tissue contour. A modified ovate pontic was used and the soft tissue was conditioned with a provisional restoration followed by a specialized impression technique aiming to record the conditioned tissue without any displacement. Esthetic emergence profile was achieved in final prosthesis without any adverse consequences on a long-term follow-up.
\end{abstract}

Keywords : Residual ridge, Ovate pontic, Impression technique.

How to cite this article: Quazi MA, Gade J, Lahoti K, Gade V. Rejuvenating the Ovate Pontic. Int J Prosthodont Restor Dent 2013;3(4):148-152.

\section{Source of support: Nil}

Conflict of interest: None

\section{INTRODUCTION}

A convex surface has always been advocated for gingival surface of any pontic design to facilitate oral hygiene. ${ }^{1}$ Ovate pontic introduced by Abrams to be used in recent extraction cases, creates the best emergence profile, but has the disadvantage of inadequate plaque control and applying pressure on ridge mucosa owing to large contact area . To overcome the disadvantages of ovate pontic, Liu modified this design by reducing the labiopalatal width without compromising the emergence profile. ${ }^{2}$

The ovate pontic when incorporated in provisional restorations can also be used to sculpt the tissue in Seibert's class I ridges. ${ }^{3}$ It was believed by some authors that pressure applied to achieve desired contour of the residual ridge resulted in soft tissue inflammation and should be contraindicated as a clinical procedure. However, Tripodakis and Constandtinides ${ }^{4}$ proved that, in patients with proper oral hygiene, well-controlled pressure with a convex and highly polished pontic resulted only in thinning of the epithelium and shortening of rete pegs without inflammation.

In order to achieve the desired esthetics in the final prosthesis, it becomes mandatory to transfer the soft tissue contour accurately to the cast so that the dental laboratory technician can fabricate a definitive restoration with an appropriate emergence profile. ${ }^{5}$ The shape of the alveolar mucosa may get distorted due to the density of the elastomeric impression material irrespective of the technique used. Also tissue collapse can occur by removal of provisional restoration and the emergence profile gets affected. Diego et al suggested a reliable impression technique especially for ovate pontics so as to get exact replica of the soft tissue contour in the cast. ${ }^{6}$

The present article describes the management of a case of poorly fabricated anterior fixed partial denture in which a modified ovate pontic along with specialized impression technique to record the soft tissue was used, and the missing anterior tooth was replaced with a CAD-CAM Zirconia based fixed partial denture.

\section{CASE REPORT}

A 27 years old male reported to the Department of Prosthetic Dentistry, Swargiya Dadasaheb Kalmegh Smruti Dental College and Hospital, Nagpur, with a chief complain of dislodged fixed partial denture in upper front region. History revealed a sport injury 3 years back causing avulsion of left central incisor following which a fixed partial denture was fabricated. Patient being a fashion model conveyed his dissatisfaction with the previous treatment due to poor esthetics and repeated dislodgement of the prosthesis. Intraoral examination revealed improper tooth preparations with 11 and 22 and Seibert's class I residual ridge and irregular contour of soft tissue with 21 . The metal ceramic fixed partial denture had poor retention and improper shade (Fig. 1). After giving due considerations to the patient's requirement, the final treatment planned was a CAD-CAM zirconia fixed partial denture with modified ovate pontic.

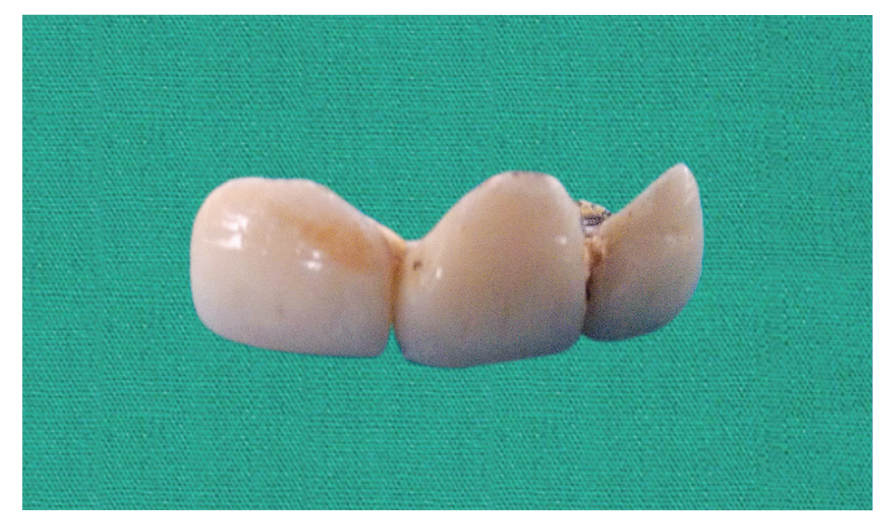

Fig. 1: Metal ceramic prosthesis 


\section{TREATMENT}

The abutment teeth 11 was root canal treated (evident on IOPA radiograph) and 22 was vital with no signs of pulp and periapical infection. The tooth preparations were modified to have adequate retention and resistance form (Figs 2 and 3).

In order to fulfill the esthetic needs of the patient, a provisional fixed partial denture was fabricated by hybrid composite resin. The gingival surface of the pontic was made convex but with a less labiopalatal dimension (Fig. 4). The controlled pressure protocol as suggested by Jacques was followed to sculpt the ridge area. ${ }^{7}$ Patient was recalled

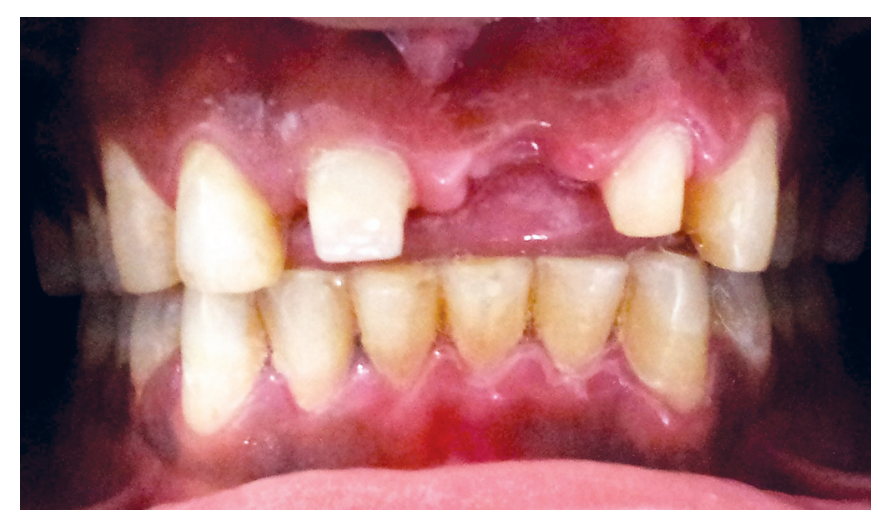

Fig. 2: Modified tooth preparations

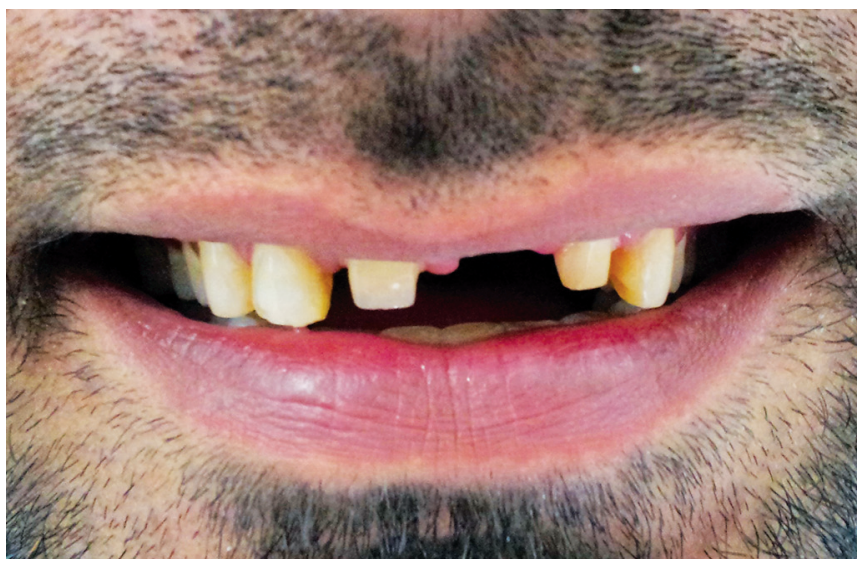

Fig. 3: Preoperative smile preparations

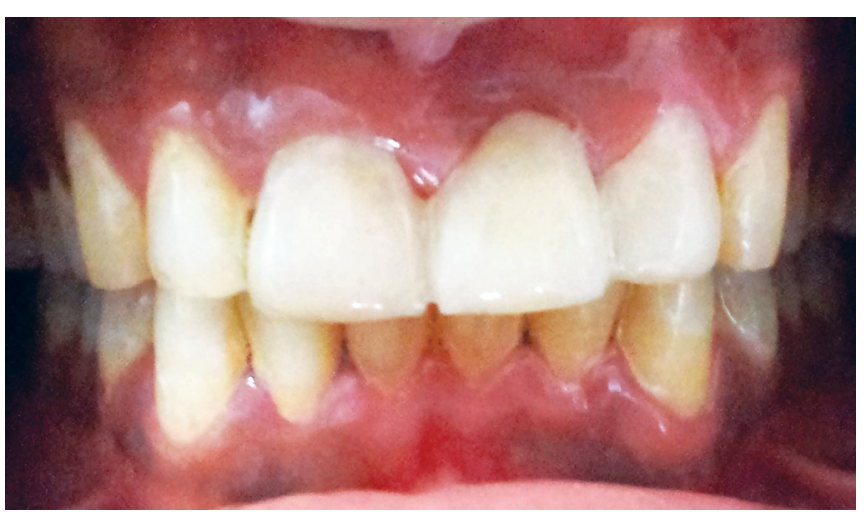

Fig. 4: Provisional prosthesis every 1 week and the contour of the gingival surface was modified by adding $1 \mathrm{~mm}$ composite resin in order to achieve adequate pressure on the soft tissue. The desired contour of the ridge area and esthetics were achieved after 3 weeks of tissue sculpting (Fig. 5).

\section{IMPRESSION PROCEDURE}

An autopolymerising acrylic resin custom tray was fabricated with two layer thickness spacer of baseplate wax and a full arch impression is made using (Aquasil) light bodied addition silicone. The cast obtained was used for the Zirconia framework fabrication (Fig. 6).

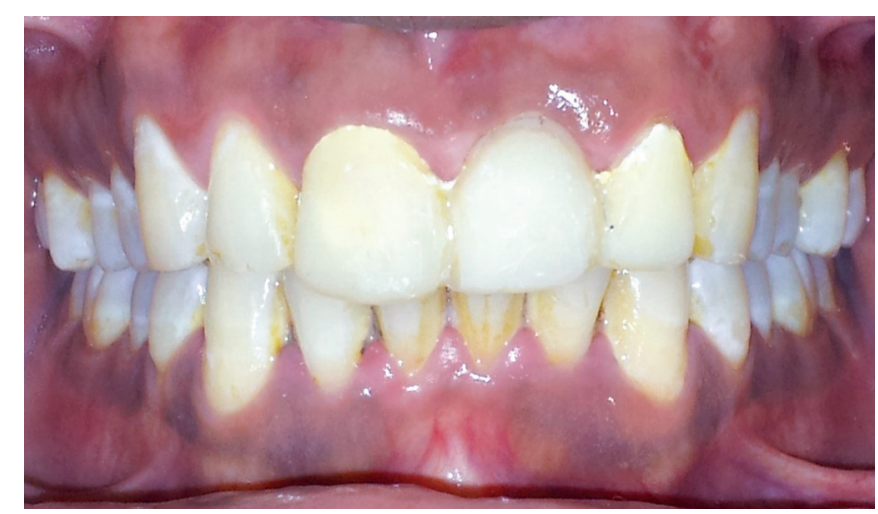

Fig. 5: Tissue contour after 3 weeks

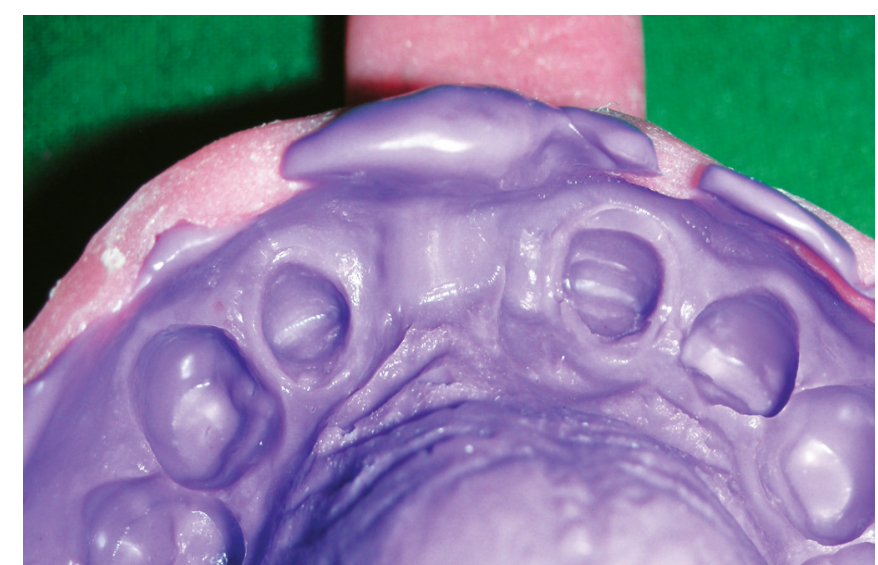

Fig. 6: Impression for framework fabrication

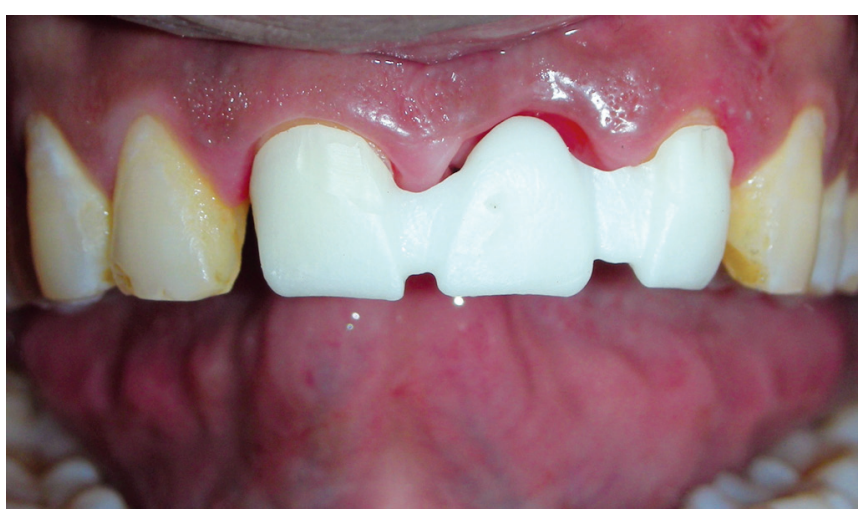

Fig. 7: Try-in of framework 
The framework was evaluated intraorally for accuracy, marginal fit and adequate clearance (Fig. 7). The provisional FPD was placed to its proper position and a transfer impression was made with Heavy body Addition Silicone so that the provisional restoration remained in the impression (Fig. 8).

The impression and provisional restoration was coated with a petroleum jelly and a cast was poured with $3 \mathrm{MESPE}$ Light bodied Addition silicone. The silicone cast so obtained replicates the sculpted tissue accurately without any distortions (Fig. 9). The final framework was seated on this cast and gingival surface was relined with selfpolymerizing acrylic resin (Fig. 10). The framework was inserted intraorally and a transfer impression was made with putty impression material. The cast was now poured with Silicone and type IV dental stone over which the final prosthesis will be fabricated (Fig. 11).

The provisional restorations was retrieved from the impression and recemented.

\section{FABRICATION AND CEMENTATION OF FINAL PROSTHESIS}

The framework was seated on the cast and the prosthesis fabrication was done with veneering ceramic to design the

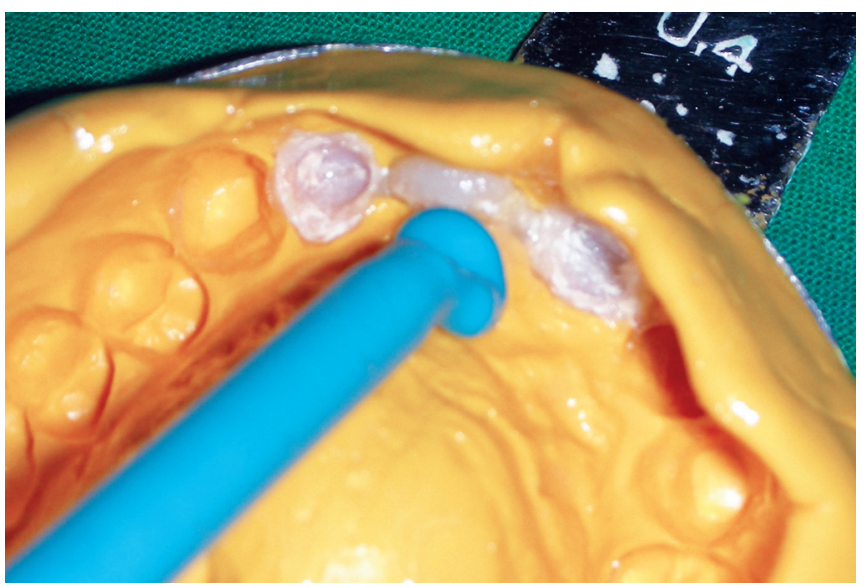

Fig. 8: Pouring of transfer impression with addition silicone

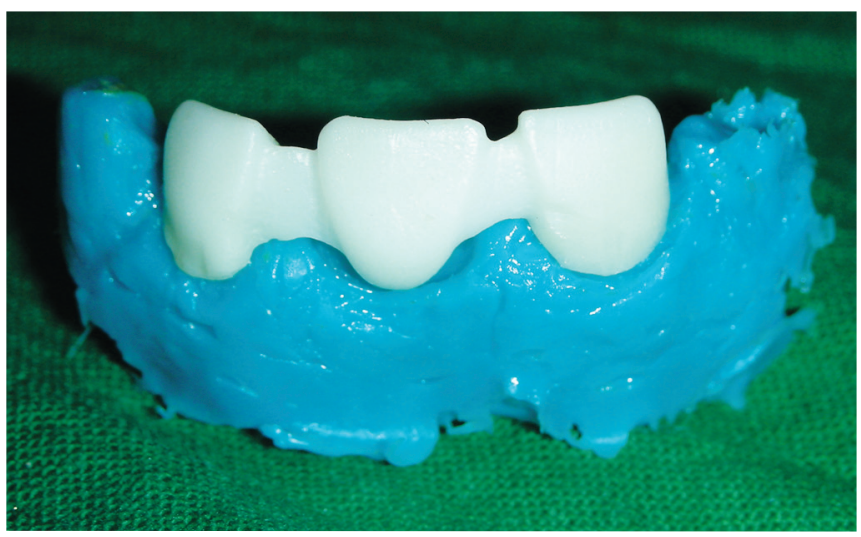

Fig. 9: Accurate reproduction of soft tissue in silicone gingival surface of the pontic approximating the tissue contour thus achieving correct emergence profile. The proper seating of prosthesis on cast was verified under magnifying glass. There was a passive fit and no rebound of prosthesis from silicone material, thus ensuring no excess pressure on soft tissue of ridge area.

The final prosthesis was evaluated in the patient's mouth for proper contour, emergence profile, shade and shape of teeth followed by final cementation (Figs 12 and 13). The patient was motivated for maintenance of oral hygiene and regular follow-up.

The patient was completely satisfied with the treatment and followed up after 1 week, 1,3 and 6 months (Fig. 14). No overt clinical signs and symptoms of inflammation were evident.

\section{DISCUSSION}

The use of ovate pontic has been rationalized in the anterior esthetic zone at the expense of oral hygiene. This problem is overcome by the modified ovate pontic developed by $\mathrm{Liu}^{2}$ which reduces the labiopalatal dimensions, conducive for oral hygiene without compromising the esthetics. The tissue surface of the pontic in the present case was convex, smooth and highly polished.

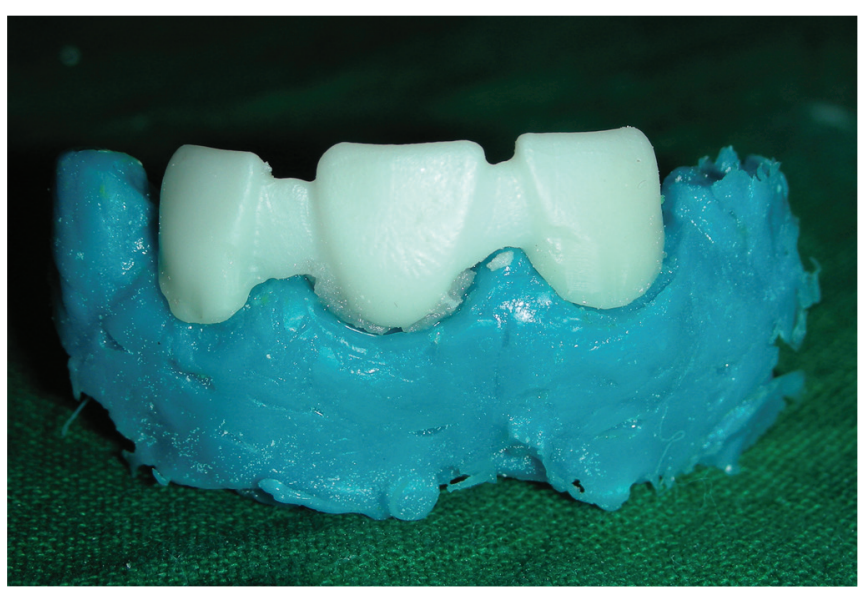

Fig. 10: Relining of gingival surface with acrylic resin

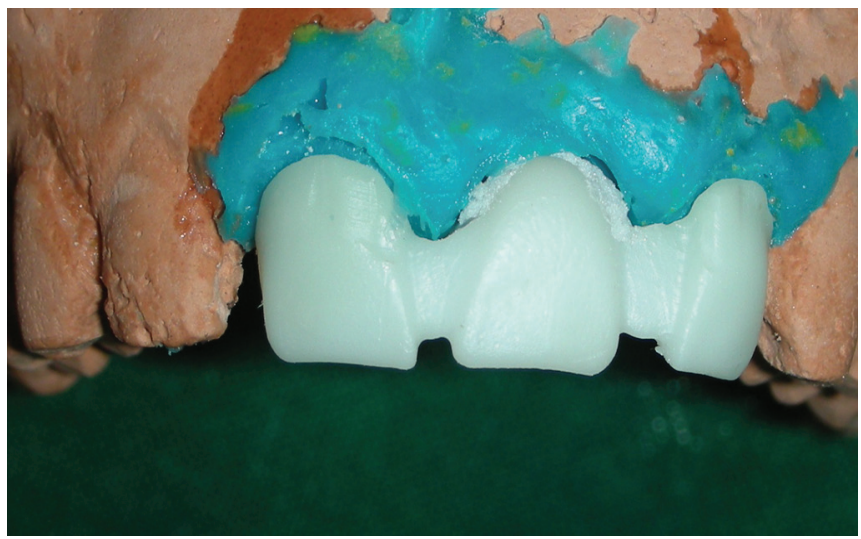

Fig. 11: Final cast obtained for fabricating final prosthesis 


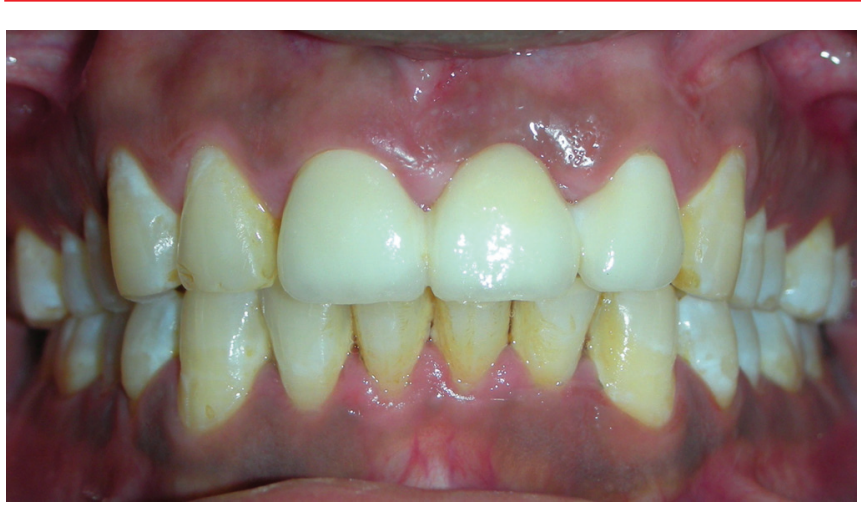

Fig. 12: Final prosthesis cemented

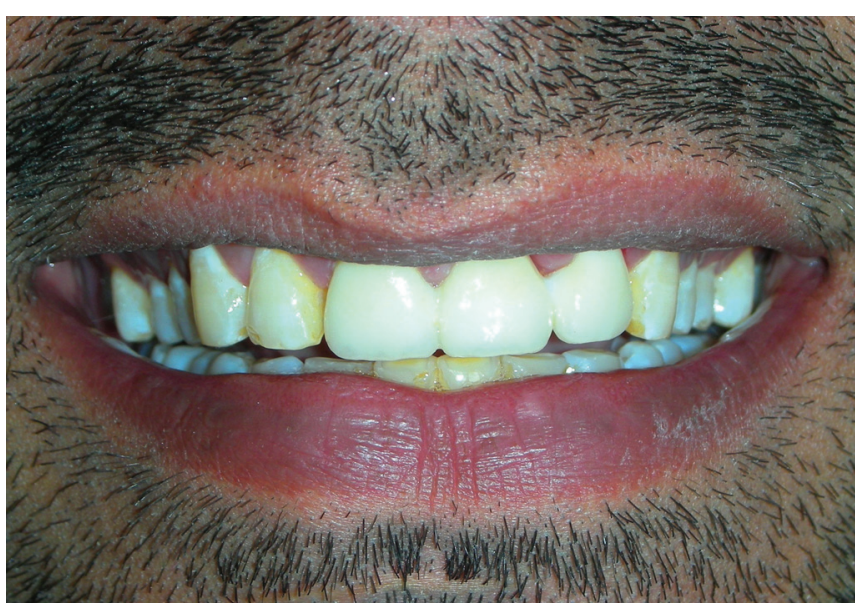

Fig. 13: Postoperative smile

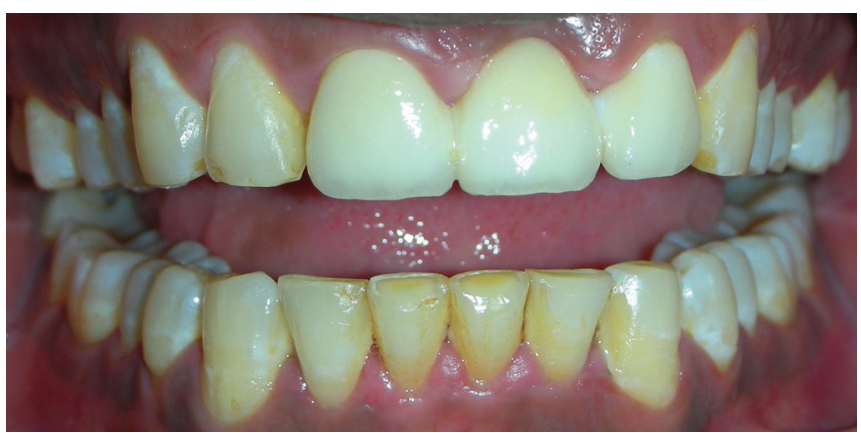

Fig. 14: Follow-up after 6 months

The controlled pressure applied by the gingival surface of provisional restoration can harnessed to achieve the desired contour of the ridge area without any overt signs of inflammation. ${ }^{8}$ The tissue sculpting technique as recommended by Jacques ${ }^{7}$ was used which is noninvasive and creates the illusion of pontic emerging from the tissue and formation of the pseudo interdental papilla.

However, a minimum 3 to $5 \mathrm{~mm}$ of soft tissue thickness is required ${ }^{8}$ to achieve optimum results so as to compress the tissue without surgical intervention. The controlled pressure can be verified easily at each appointment by ensuring, that the blanching of soft tissue after pressure application by provisional restoration subsides within 5 to 10 minutes to avoid excessive pressure on soft tissue. ${ }^{9}$

The accurate transfer of the soft tissue contour to the cast is important to achieve proper emergence profile. Hence, the impression technique deviced by Diego et al was used. The relining of the gingival surface of the pontic with acrylic resin in the framework holds the soft tissue in its contoured position and the pick-up impression of the relined framework ensures transfer of the contour and its orientation relative to the abutment teeth. An esthetic emergence profile can thus be obtained in a more predictable manner.

A Zirconia CAD-CAM based prosthesis was used to address the esthetic needs of the patient and also have adequate strength ensuring longevity of the prosthesis.

\section{CONCLUSION}

A modified ovate pontic with reduced labiopalatal dimensions can be used wisely to achieve good esthetics without compromising oral hygiene. A gradual application of controlled pressure to edentulous ridge transforms irregular ridge area into a well prepared ridge to accommodate pontic with appropriate emergence profile. Nevertheless, the accurate reproduction of the tissues is mandatory to achieve the desired results and should be meticulously followed.

\section{REFERENCES}

1. Cavazos E. Tissue response to fixed partial pontics. J Prosthet Dent 1968;20:143-153.

2. Liu CL. Use of a modified ovate pontic in areas of ridge defects: a report of two cases. J Esthet Restor Dent 2004;16:273-283.

3. Seibert JS. Reconstruction of deformed, partially edentulous ridges, using full thickness onlay grafts. Part II. Prosthetic/ periodontal interrelationships. Compend Contin Educ Dent 1983;4:549-562.

4. Tripodakis A, Constandtinides A. Tissue response under hyperpressure from convex pontics. Int J Periodontics Restorative Dent 1990;10:409-414.

5. Dylina TJ. Contour determination for ovate pontics. J Prosthet Dent 1999;82:136-142.

6. Diego Klee de Vasconcellos. Impression technique for ovate pontics. J Prosthet Dent 2010;105:59-61.

7. Jacques LB, Coelho AB, Hollweg H, Conti PC. Tissue sculpturing: an alternative method for improving esthetics of anterior fixed prosthodontics. J Prosthet Dent 1999;81:630-633.

8. Zitzmann NU, Marinello CP, Berglundh T. The ovate pontic design: a histologic observation in humans. J Prosthet Dent 2002;88:375-380.

9. Kim TH, Cascione D, Knezevic A. Simulated tissue using a unique pontic design: a clinical report. J Prosthet Dent 2009; 102:205-210. 


\section{ABOUT THE AUTHORS}

\section{Mohsin Atibuddin Quazi (Corresponding Author)}

Postgraduate Student, Department of Prosthodontics, Swargiya Dadasaheb Kalmegh Smruti Dental College and Hospital, Nagpur Maharashtra, India, Phone: 9158886474, e-mail: dr.mohsinquazi@ gmail.com

\section{Jaykumar Gade}

Head, Department of Prosthodontics, Swargiya Dadasaheb Kalmegh Smruti Dental College and Hospital, Nagpur, Maharashtra, India

\section{Krishnakumar Lahoti}

Reader and Postgraduate Guide, Department of Prosthodontics Swargiya Dadasaheb Kalmegh Smruti Dental College and Hospital Nagpur, Maharashtra, India

\section{Vandana Gade}

Professor and Guide, Department of Conservative Dentistry and Endodontics, Swargiya Dadasaheb Kalmegh Smruti Dental College and Hospital, Nagpur, Maharashtra, India 